\title{
Simultaneous detection of a-Lactoalbumin, $\beta$-Lactoglobulin and Lactoferrin in milk by Visualized Microarray
}

\author{
Zhoumin $\mathrm{Li}^{1,2}$, Fang Wen ${ }^{3}$, Zhonghui $\mathrm{Li}^{1}$, Nan Zheng ${ }^{3^{*}}$, Jindou Jiang ${ }^{4}$ and Danke $\mathrm{Xu}^{1^{*}}$
}

\begin{abstract}
Background: a-Lactalbumin (a-LA), $\beta$-lactoglobulin ( $\beta-L G$ ) and lactoferrin (LF) are of high nutritional value which have made ingredients of choice in the formulation of modern foods and beverages. There remains an urgent need to develop novel biosensing methods for quantification featuring reduced cost, improved sensitivity, selectivity and more rapid response, especially for simultaneous detection of multiple whey proteins.

Results: A novel visualized microarray method was developed for the determination of a-LA, $\beta-L G$ and LF in milk samples without the need for complex or time-consuming pre-treatment steps. The measurement principle was based on the competitive immunological reaction and silver enhancement technique. In this case, a visible array dots as the detectable signals were further amplified and developed by the silver enhancement reagents. The microarray could be assayed by the microarray scanner. The detection limits $(S / N=3)$ were estimated to be $40 \mathrm{ng} / \mathrm{mL}$ (a-LA), $50 \mathrm{ng} / \mathrm{mL}$ ( $\beta-\mathrm{LG}), 30 \mathrm{ng} / \mathrm{mL}(\mathrm{LF})(n=6)$.

Conclusions: The method could be used to simultaneously analyze the whey protein contents of various raw milk samples and ultra-high temperature treated (UHT) milk samples including skimmed milk and high calcium milk. The analytical results were in good agreement with that of the high performance liquid chromatography. The presented visualized microarray has showed its advantages such as high-throughput, specificity, sensitivity and cost-effective for analysis of various milk samples.
\end{abstract}

Keywords: Visualized microarray, a-Lactoalbumin, $\beta$-Lactoglobulin, Lactoferrin

\section{Background}

Milk whey protein represents a rich and mixture proteins with wide ranging nutritional, biological and food functional attributes. The main constituents are $\alpha$-lactalbumin $(\alpha$-LA), $\beta$-lactoglobulin ( $\beta$-LG) and lactoferrin (LF), which account for approximately $70-80 \%$ of total whey protein. $\alpha$-LA, $\beta$-LG and LF are of high nutritional value which have made ingredients of choice in the formulation of modern foods and beverages. They may also have physiological activity through moderating gut microflora, mineral absorption and immune function [1, 2].

\footnotetext{
*Correspondence: zhengnan_1980@126.com; xudanke@nju.edu.cn

${ }^{3}$ Ministry of Agriculture-Key Laboratory of Quality \& Safety Control for Milk and Dairy Products, Institute of Animal Science, Chinese Academy of Agricultural Sciences, Beijing 100193, People's Republic of China

'State Key Laboratory of Analytical Chemistry for Life Science, School of Chemistry and Chemical Engineering, Nanjing University, Nanjing 210093, China

Full list of author information is available at the end of the article
}

Although several methods have been reported for $\alpha$-LA, $\beta$-LG and LF, either alone or concomitant with other whey proteins, including chromatographic analysis (High performance liquid chromatography (HPLC) [3-11], Ultra high performance liquid chromatography (UHPLC) [12], High performance liquid chromatography -mass spectra (HPLC-MS) [13-21], Ultra high performance liquid chromatography - mass spectra (UHPLC-MS) [22-27], Immunoaffinity chromatography (IAC) [26, 27]), Radial Immunodiffusion (RID) [28], sodium dodecyl sulfate polyacrylamide gel electropheresis (SDS-PAGE) [29, 30], Capillary Electrophoresis(CE) [10, 31-34], Enzymellinked Immunosorbent Assay (ELISA) [17, 35-42], Fluorescent Immunosorbent Assay(FIA) [43, 44], Surface Plasmon Resonance (SPR) [45-49] and Sensors [5052]. In general, chromatographic analysis requires pretreated samples, high initial sample volumes and long analysis times, which lead to high cost. In addition, analytical 
chromatographic technologies are unable to identify protein denaturation or modification that may occur during processing and storage. This is an important factor for public health and food commodities marketing. Some of these drawbacks can be overcome using traditional immunological methods, such as ELISA. It also offers the advantages of working directly with complex fluids, such as whole milk and other dairy fluids, but only one whey protein can be detected. However, there remains an urgent need to develop alternative methods for quantification featuring reduced cost, improved sensitivity, selectivity and more rapid response, especially for simultaneous detection of multiple whey proteins.

Development of new tools, minimizing limitations imposed by these methodologies and leveraging the high specificity of traditional immunological methods, is of great interest. In this sense, visualized microarray are envisaged as a valid alternative to classical methods for analysis of protein, because they are amenable to direct readout by eyes and well suited to rapid detection with high sensitivity and selectivity using low-cost instrumentation that is adaptable to portable, field-deployable embodiments, which is ideal for routine determination in the dairy industry [53-56].

In this paper, we described the development of visualized microarray method for simultaneous, high-throughput quantitative immune-detection of three commercially important whey proteins $(\alpha-\mathrm{LA}, \beta-\mathrm{LG}$, and LF) in samples at a time, from various milk sources. To the best of our knowledge, no visualized microarray has been described thus far for the determination of a-LA, $\beta$-LG, and LF simultaneously. Visualized microarray method allowed the analysis of milk without the need for sample preparation, including pre-enrichment or purification steps, "extraction" of target analytes from the complex matrix, and measurement of signal in a "clean" environment. The assay was then used to simultaneously analyze the whey protein contents of various raw milk samples and UHT milk samples including skimmed milk and high calcium milk and the analytical results were in good agreement with that of the HPLC.

\section{Methods}

\section{Materials and instruments}

$\alpha$-LA, $\beta$-LG, LF and silver enhancement solution including solution $\mathrm{A}\left(\mathrm{AgNO}_{3}\right)$ and solution $\mathrm{B}$ (Hydroquinone) were all purchased from Sigma-Aldrich. $\mathrm{NaCl}, \mathrm{KCl}$, $\mathrm{Na}_{2} \mathrm{HPO}_{4} \cdot 12 \mathrm{H}_{2} \mathrm{O}, \mathrm{KH}_{2} \mathrm{PO}_{4}$, Tween-20, Ethylenediaminetetraacetic acid (EDTA) was from Nanjing Chemical Reagent Co., Ltd. (Nanjing, China). Pure water of 18.2 $\mathrm{M} \Omega \mathrm{cm}-1$ was generated in-lab from a Milli-Q water system. Bovine serum albumin (BSA) was purchased from Merck. Goat polyclonal to $\alpha$-lactalbumin $(\alpha-\mathrm{LA})$, goat polyclonal to $\beta$-lactoglobulin ( $\beta$-LG), goat polyclonal to lactoferrin (LF) and AgNPs labeled donkey anti-goat IgG were kindly supplied by Nanjing Xiangzhong Biotechnology Co. Ltd. (Nanjing, China).

All solutions were made by triply deionized water (Milli-Q water purification system, Millipore, Billerica, MA, USA). A $10 \mathrm{mM}$ phosphate buffered saline (PBS) at $\mathrm{pH} 7.2$ was used as the assay buffer which was prepared as following: $137 \mathrm{mmol} / \mathrm{L} \mathrm{NaCl}, 2.7 \mathrm{mmol} / \mathrm{L} \mathrm{KCl}$, $10 \mathrm{mmol} / \mathrm{L} \mathrm{Na}_{2} \mathrm{HPO}_{4} \cdot 12 \mathrm{H}_{2} \mathrm{O}$ and $2 \mathrm{mmol} / \mathrm{L} \mathrm{KH}_{2} \mathrm{PO}_{4}$. A $10 \mathrm{mM}$ PBS containing $0.01 \%$ Tween-20 and $1 \mathrm{mM}$ EDTA (PBST- EDTA) at pH 7.2 was used for milk sample preparation and dilution. The wash buffer was a PBS containing $0.05 \%$ Tween 20 (PBST). The blocking solution was $1 \%$ BSA in $10 \mathrm{mM}$ PBS. All buffers were filtered through $0.22 \mu \mathrm{m}$ pore size filter before use.

The microarrays were prepared by TMAR microarray spotter (Tsinghua University, Beijing, China). Automated plate washer (BioTek Instruments, Inc. America) was used as washing platform. LXJ-II centrifuge (Shanghai Anting Instrument Co., Shanghai, China) were used for the centrifugation. Clear flat-bottom 96-well plate, thermo-shaker and microarrays scanner (QARRAY 2000) were from Nanjing Xiangzhong Biotechnology Co. Ltd. (Nanjing, China).

\section{Microarray preparation}

The obtained of $\alpha$-LA, $\beta$-LG and LF were spotted on clear flat-bottom 96-well plate. A volume of $10 \mu \mathrm{L}$ of each coating antigens diluted by spotting buffer were arrayed with a $500 \mu \mathrm{m}$ spot-to-spot pitch using a microarray spotter, each antigen solutions was in triplicate. After spotted, microarray was incubated for $2 \mathrm{~h}$ at $37^{\circ} \mathrm{C}$. In this step the coating antigens were immobilized on the microplate wells by absorption over the surface of the support of polystyrene. After immobilization, microarray surface was treated with $200 \mu \mathrm{L} 1 \%$ BSA for $1 \mathrm{~h}$ at $37{ }^{\circ} \mathrm{C}$ in order to minimize further unspecific bindings. After incubation, the microarray plate was washed with $1 \times$ PBST buffer using an automated plate washer and then sealed in foil packets for storage at $2-8{ }^{\circ} \mathrm{C}$.

\section{Indirect competitive microarray immunoassay protocol}

The indirect competitive microarray immunoassay principle was presented in Scheme 1. In a microarray immunoassay analysis the following experimental procedure was performed. The competition is established by the addition of a mixture of $25 \mu \mathrm{L}$ the standard (or the sample), a known amount of $25 \mu \mathrm{L}$ mixed antibodies, The reaction is incubated at $25{ }^{\circ} \mathrm{C}$ for $45 \mathrm{~min}$ on a thermoshaker (shaking at $600 \mathrm{rpm}$ ). After the corresponding washing step, AgNPs labeled donkey anti-goat IgG in a total volume of $50 \mu \mathrm{L} /$ well. The reaction is incubated at $37^{\circ} \mathrm{C}$ for $30 \mathrm{~min}$ on a thermoshaker (shaking at $600 \mathrm{rpm}$ ). After the corresponding washing step, $50 \mu \mathrm{L}$ silver enhancement solution including solution $\mathrm{A}\left(\mathrm{AgNO}_{3}\right)$ and solution $\mathrm{B}$ (Hydroquinone) was then added to each well, and incubated for $12 \mathrm{~min}$ at $37^{\circ} \mathrm{C}$ 


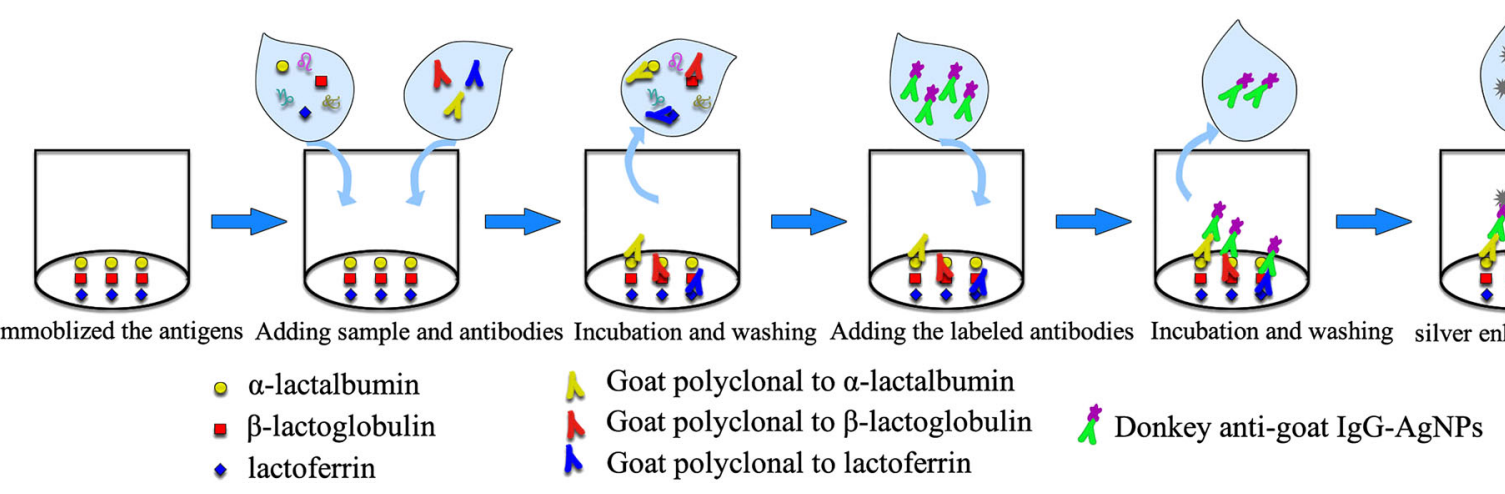

Scheme 1 Schematic illustration of detection a-lactalbumin ( $a-L A)$, $\beta$-lactoglobulin ( $\beta$-LG) and lactoferrin(LF) with visualized microarray immunoassay platform, composed of silver enhancement amplification system

in dark. At the end of colorimetric reaction, each well was washed 3 times with $250 \mu \mathrm{L}$ pure water.

\section{Microarray imaging and data processing}

The microarray was imaged with microarray scanner (QARRAY 2000) and performed using the corresponding software to quantify the signal over the sample spot area and expressed as relative light units (RLUs). The calibration curve was represented by a linear relationship. able to produce an equal signal as when the analyte is assayed to provoke a signal inhibition of $50 \%$. Therefore, in this work CR rates, in terms of percentage (\%), were calculated according to the expression (eq. 1).

$$
\mathrm{CR}=\left[\left(\mathrm{IC}_{50}(\text { analyte }) / \mathrm{IC}_{50}(\text { interference })\right)\right] \times 100 \%
$$

\section{Cross reactivity calculation}

Cross reactivity $(\mathrm{CR})$ is generally defined as the necessary amount of mass or concentration of interference

$\mathrm{IC}_{50}$ is the necessary concentration of analyte or interference to induce a signal inhibition of $50 \%$.

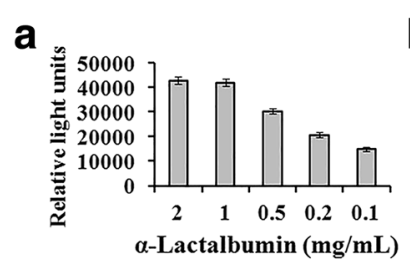

d

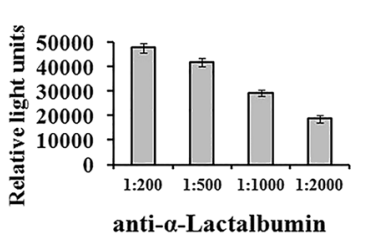

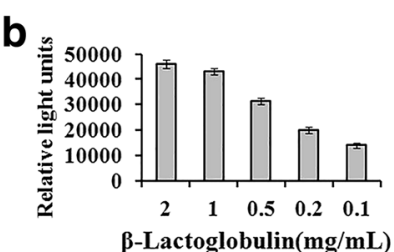

e

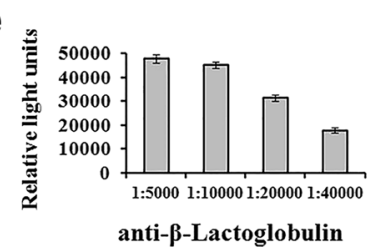

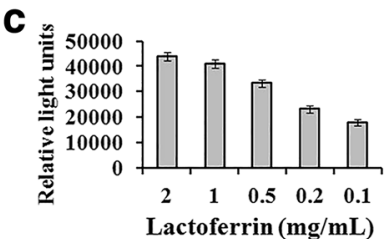

f

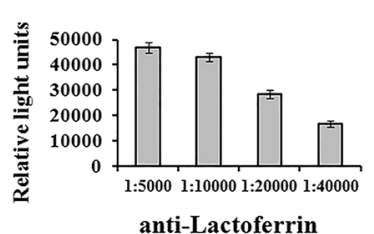

g

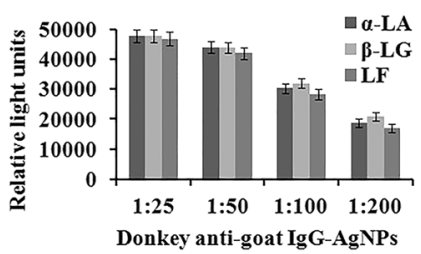

Fig. 1 a, b, c coating antigens of $a-L A, \beta-L G$ and LF were $2 \mathrm{mg} / \mathrm{mL}, 1 \mathrm{mg} / \mathrm{mL}, 0.5 \mathrm{mg} / \mathrm{mL}, 0.2 \mathrm{mg} / \mathrm{mL}, 0.1 \mathrm{mg} / \mathrm{mL}$, respectively; $\mathbf{d}$ anti- $\mathrm{a}-\mathrm{LA}$ were 1:200, 1:500, 1:1000, 1:2000 dilution respectively; e anti- $\beta$-LG were 1:5000, 1:10,000, 1:20,000, 1:40,000 dilution respectively; $\mathbf{f}$ anti-LF were 1:5000, 1:10,000, 1:20,000, 1:40,000 dilution respectively; $\mathbf{g}$ second antibodies of AgNPs labeled donkey anti-goat lgG were 1:25, 1:50, 1:100, 1:200 dilution respectively for $a-L A, \beta-L G$ and $L F$ 


\section{Milk samples}

Milk consists of metal ions such as calcium, iron, magnesium and zinc. For actual sample analysis, it should be considered that $\alpha$-LA, $\beta-L G$ and LF had a high possibility of forming chelation complex with these metal ions. Thus, prior to actual sample analysis, milk was diluted 200-fold with PBST-EDTA at pH 7.2. Milk was purchased from local supermarket.

\section{HPLC method \\ Solutions}

Binding buffer (BB): $1.211 \mathrm{~g}$ Tris was dissolved with $800 \mathrm{~mL} 6 \mathrm{~mol} / \mathrm{L} \mathrm{HCl}$, adjusted to $\mathrm{pH} 7.4$ and then volumed to final volume to $1000 \mathrm{~mL}$.

Elution buffer (EB): $0.15 \mathrm{~mol} / \mathrm{L}$ sodium phosphate, pH 12.

Buffer for adjusting $\mathrm{pH}$ of $\mathrm{EB}(\mathrm{AB}): 1 \mathrm{~mol} / \mathrm{L}$ sodium dihydrogen phosphate.

\section{Treatment of milk sample for analysis $\alpha$ - Lactalbumin and $\beta$ - lactoglobulin}

$5 \mathrm{~mL}$ milk sample was mixed with $14 \mathrm{~mL}$ water and adjusted to $\mathrm{pH}$ 4.6. Next water was added to the mixture making final volume to $20 \mathrm{~mL}$. Then the above mixture was centrifugated under $10,000 \mathrm{rpm}$ and $4{ }^{\circ} \mathrm{C}$ for $10 \mathrm{~min}$. Finally, supernatant was filter with $0.22 \mu \mathrm{m}$ filter and injected to HPLC system.

\section{Treatment of milk sample for analysis lactoferrin}

Milk samples were centrifugated under $8000 \mathrm{~g}$ and $4{ }^{\circ} \mathrm{C}$ for $10 \mathrm{~min}$ to remove fat. Then $15 \mathrm{~mL}$ skim milk was loaded onto lactoferrin immune-affinity column that was pre-equilibrated with $10 \mathrm{~mL} \mathrm{BB}$. After washing with $20 \mathrm{~mL} \mathrm{BB}$, lactoferrin was eluted with $3.6 \mathrm{~mL}$ EB. Then the $3.6 \mathrm{~mL}$ elution was mixed with $0.4 \mathrm{~mL}$ EB. Finally the mixture was filtered with $0.22 \mu \mathrm{m}$ filter and injected to HPLC system. The lactoferrin immune-affinity column was washed with $10 \mathrm{~mL} \mathrm{BB}$ and stored at $4{ }^{\circ} \mathrm{C}$ for further use.

\section{HPLC system}

The chromatographic analysis of lactoferrin was carried out on a HPLC system (2695 Separations Module, Waters; Milford, MA, USA) coupled with a photodiode array detector (PDA 2996 detector, Waters; Milford, MA, USA). Separation was performed using a Symmetry C4 Column (300 ̊, $5 \mu \mathrm{m}, 4.6 \mathrm{~mm} \times 250 \mathrm{~mm}$, Waters). Acetonitrile (eluent A) and $0.1 \%$ trifluoroacetic acid in water (eluent B) were used as mobile phase. The flow rate was set at $1.0 \mathrm{~mL} / \mathrm{min}$ and the LC elution gradient was as follows: initial 30\% A, 5 min 55\% A, $10 \min 60 \%$ A, 12 min 30\% A and hold on for a further $4 \mathrm{~min}$ for re-equilibration, giving a total run time $16 \mathrm{~min}$. The column temperature was kept at $25{ }^{\circ} \mathrm{C}$ and the injection volume was $50 \mu \mathrm{L}$ for

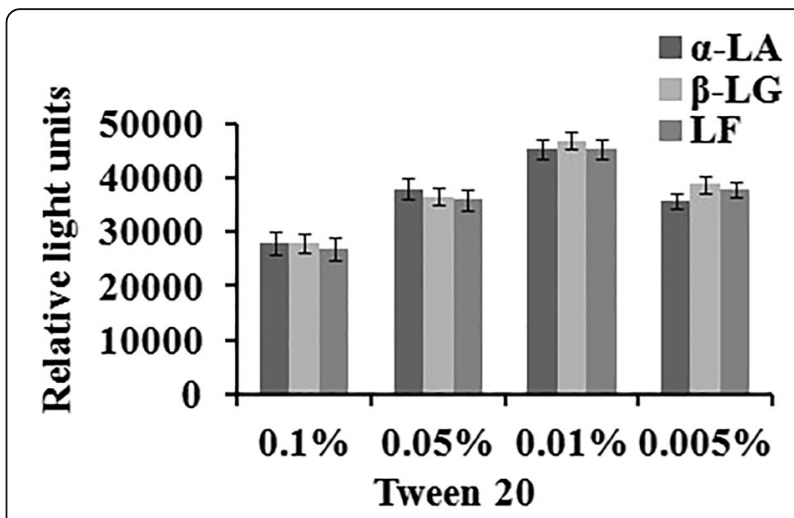

Fig. 2 The dilutions of Tween 20 were $0.1 \%, 0.05 \%, 0.01 \%, 0.005 \%$ respectively for $a-L A, \beta-L G$ and $L F$. Antigen of $a-L A, \beta-L G$ and $L F$ were all $1 \mathrm{mg} / \mathrm{mL}$; anti-a-LA, anti- $\beta-L G$ and anti-LF were 1:500, 1:10,000 and 1:10,000 dilution respectively; Second antibodies of AgNPs labeled donkey anti-goat lgG 1:50 dilution

standards and sample solutions. The wavelengths was set at $280 \mathrm{~nm}$ for detection. Waters Empower 2.0 chromatography software package was used for HPLC system control, data acquisition and management.

\section{Results and discussion \\ Optimization}

To develop a highly sensitive and specific indirect competitive immunoassay, the conditions including the concentrations of coating antigens and antibodies, should be carefully optimized by a checkboard titration of antigen and antibody simultaneously. In addition, it was necessary to evaluate the effect of presence or absence of EDTA and Tween 20 in assay buffer.

\section{Concentrations of coating antigens and antibodies}

To develop highly sensitive competitive immunoassay, the conditions including the concentrations of coating antigens and dilutions of antibodies should be carefully optimized. In this study, coating antigens of $\alpha-\mathrm{LA}, \beta-\mathrm{LG}$ and LF all were $2 \mathrm{mg} / \mathrm{mL}, 1 \mathrm{mg} / \mathrm{mL}, 0.5 \mathrm{mg} / \mathrm{mL}, 0.2 \mathrm{mg} / \mathrm{mL}$, $0.1 \mathrm{mg} / \mathrm{mL}$, respectively; anti- $\alpha$-LA were 1:200, 1:500,

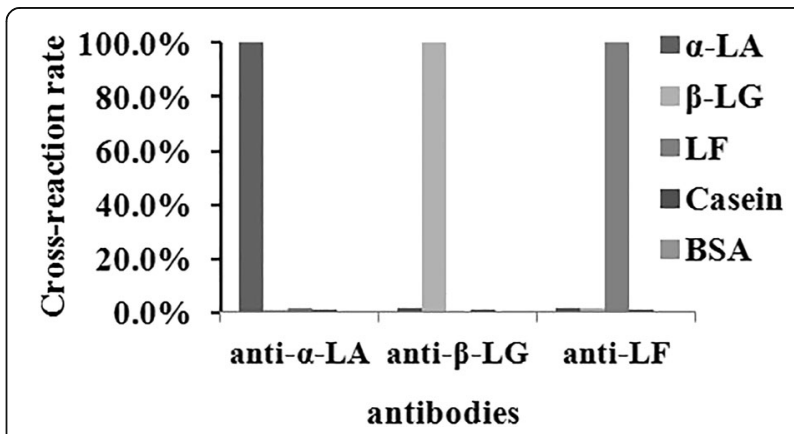

Fig. 3 Anti- $\alpha-L A$, anti- $\beta-L G$ and anti-LF were cross-reactivity with $a-L A$, $\beta-L G, L F$, Casein and BSA 


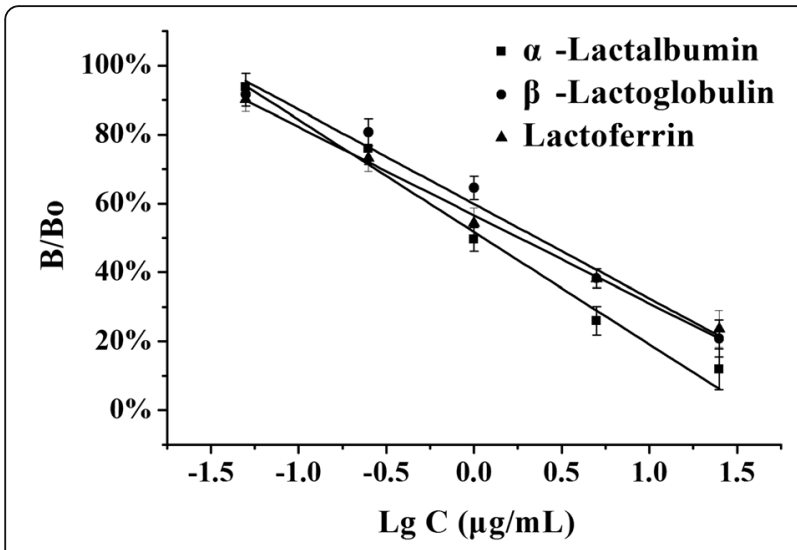

Fig. 4 Calibration curves of $a-L A, \beta-L G$ and LF. $a-L A: y=-0.3258 x$ $+0.5171, r=0.9829 ; \beta$-LG: $y=-0.2738 x+0.5986, r=0.9702 ;$ LF: $y=-0.2558 x+0.5658, r=0.9952$

1:1000, 1:2000 dilution respectively; anti- $\beta$-LG were 1:5000, 1:10,000, 1:20,000, 1:40,000 dilution respectively; anti-LF were 1:5000, 1:10,000, 1:20,000, 1:40,000 dilution respectively. In addition, second antibodies of AgNPs labeled donkey anti-goat IgG were 1:25, 1:50, 1:100, 1:200 dilution respectively. The results can be seen in Fig. 1 .

Lower the concentration of antigen and antibody can increase detection sensitivity, but the signal value will be lower. So the optimal assay conditions were as follows: Appropriate concentrations of $\alpha$-LA, $\beta$-LG and LF were all $1 \mathrm{mg} / \mathrm{mL}$; The appropriate concentrations of anti- $\alpha-\mathrm{LA}$, anti- $\beta$-LG and anti-LF were 1:500, 1:10,000 and 1:10,000 dilution respectively; Appropriate concentrations of second antibodies of AgNPs labeled donkey anti-goat IgG were 1:50 dilution.

\section{Effect of EDTA and Tween 20}

However, milk has metal ions such as calcium, iron, magnesium, potassium, sodium and zinc ion, so it is necessary to consider the high potential for forming chelating complexes between $\alpha$-LA, $\beta$-LG and LF with these metal ions. To prevent these interferences, EDTA was incorporated in the assay buffer. EDTA has a greater affinity for the calciums than $\alpha$-LA, $\beta$-LG and LF, thus it can block the interaction of $\alpha-L A, \beta-L G$, LF with calciums.

Tween 20 is a non-ionic surfactant, which has emulsification, diffusion, solubilization, stabilizing effect with samples. Moreover, it provides a protective of antigenantibody in buffers, and reduces the nonspecific binding of antibodies to antigens and interfering proteins. Thus it can reduce the background and improve the sensitivity. However, an excessive concentration could inhibit binding of antibody and antigen. Finally, Tween 20 concentration was selected to be $0.01 \%$. The results can be seen in Fig. 2.

\section{Method development}

Assay specificity indicates the ability of antibody to generate a measurable response only for the target molecule. The cross-reactivity of antibodies was evaluated under indirect competitive immunoassay conditions in order to confirm specificity. Here, a study was performed using five main proteins in milk, such as $\alpha$-LA, $\beta$-LG, LF, Casein and BSA. The cross-reactivity studies were carried out by adding various free cross reactants at different concentrations to compete with antigen coated on the surface, to bind with the antibody. The cross-reactivity for each compound was calculated according to the expression (eq. 1) and given in Fig. 3.

The anti- $\alpha-\mathrm{LA}$, anti- $\beta-\mathrm{LG}$, anti-LF were determined to be highly specific for $\alpha$-LA, $\beta$-LG, LF respectively, although there was a minor dose-response relationship for Casein and BSA (cross-reactivity $<1.0 \%$ ), the binding responses for these proteins were analytically insignificant at

Table 1 The recoveries of different concentrations of a-Lactalbumin, $\beta$-Lactoglobulin, Lactoferrin

\begin{tabular}{|c|c|c|c|c|c|}
\hline Proteins & Spiked concentration $(\mu \mathrm{g} / \mathrm{mL})$ & Average $(\mu \mathrm{g} / \mathrm{mL})$ & $\mathrm{SD}(\mu \mathrm{g} / \mathrm{mL})$ & RSD & recovery \\
\hline \multirow[t]{4}{*}{ a-Lactalbumin } & 20 & 18.23 & 2.14 & $11.74 \%$ & $91.15 \%$ \\
\hline & 100 & 108.19 & 12.27 & $11.34 \%$ & $108.19 \%$ \\
\hline & 400 & 409.81 & 40.57 & $9.90 \%$ & $102.45 \%$ \\
\hline & 2000 & 2032.93 & 252.61 & $12.43 \%$ & $101.65 \%$ \\
\hline \multirow[t]{4}{*}{$\beta$-Lactoglobulin } & 20 & 19.13 & 2.56 & $13.38 \%$ & $95.65 \%$ \\
\hline & 100 & 105.77 & 11.76 & $11.12 \%$ & $105.77 \%$ \\
\hline & 400 & 419.8 & 48.36 & $11.52 \%$ & $104.95 \%$ \\
\hline & 2000 & 2131.46 & 206.85 & $9.70 \%$ & $106.57 \%$ \\
\hline \multirow[t]{4}{*}{ Lactoferrin } & 20 & 19.13 & 2.76 & $14.43 \%$ & $95.65 \%$ \\
\hline & 100 & 95.77 & 12.08 & $12.61 \%$ & $95.77 \%$ \\
\hline & 400 & 402.81 & 40.36 & $10.02 \%$ & $100.70 \%$ \\
\hline & 2000 & 1931.46 & 263.44 & $13.64 \%$ & $96.57 \%$ \\
\hline
\end{tabular}




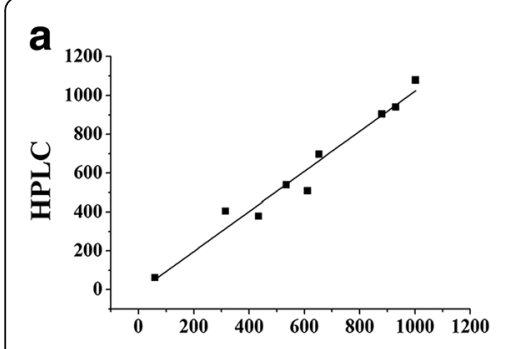

Visualized Microarry - $\alpha$-Lactalbumin $(\mu \mathrm{g} / \mathrm{mL})$

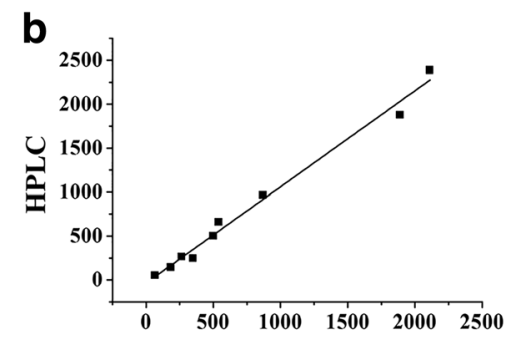

Visualized Microarry - $\beta$-Lactoglobulin $(\mu \mathrm{g} / \mathrm{mL})$

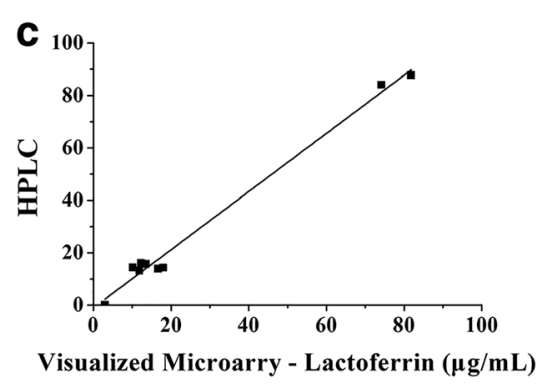

Fig. 5 Results obtained by visualized microarray and HPLC are plotted against each other. a a-Lactalbumin, b $\beta$-Lactoglobulin, c Lactoferrin

concentrations equivalent to those of diluted milk samples.

\section{Method performance}

In order to be able to determine multiplex format concentrations of $\alpha$-LA, $\beta$-LG and LF, the assay was calibrated independently using a cocktail of the $\alpha$-LA, $\beta-L G, L F$ antibodies and different concentrations of $\alpha$-LA, $\beta$-LG and LF. As a matter of fact, the competition occurs for all target molecules and the specific signal obtained on each probe decreases with the analyte concentration, as expected in a competitive immunoassay.

Over the optimized working calibration range ( $\alpha$-LA, $\beta$-LG and LF were all $0.05,0.25,1,5,25 \mu \mathrm{g} / \mathrm{mL})$, a semilog curve fit adequately described the dose-response relationship which can be seen in Fig. 4. Their calibration curves were calculated as follows, $\alpha-L A: y=-0.3258 \times$

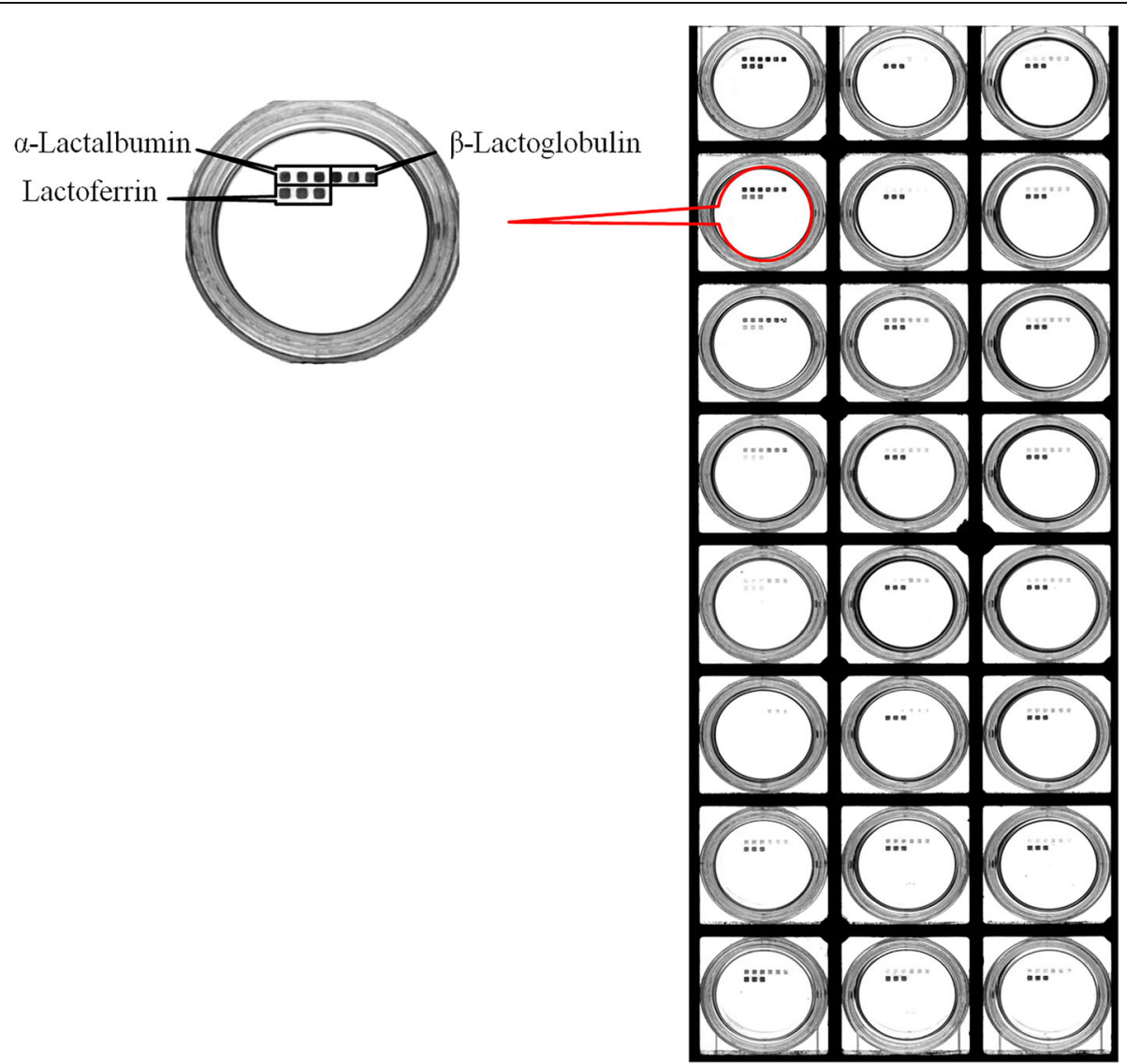

Fig. 6 Results of a-LA, $\beta-L G$, and LF were detected by Visualized Microarray. From top to bottom, left to right was numbered 1 to 18. 1-7 were raw milk, 8-11 were pasteurized milk, 12-18 were UHT milk including skimmed milk and high calcium milk 
$+0.5171, r=0.9829 ; \beta$-LG: $\mathrm{y}=-0.2738 \mathrm{x}+0.5986$, $r=0.9702$; LF: $\mathrm{y}=-0.2558 \mathrm{x}+0.5658, r=0.9952$. In the calculation formula, $\mathrm{y}: \mathrm{B} / \mathrm{B} 0 \%, \mathrm{x}: \lg \mathrm{C}$. $(\mathrm{B} / \mathrm{B} 0$ is the ratio of response $B$ to the maximum response when no analyte is present $\mathrm{B} 0$.)

The method detection limits (response 3 standard deviations of blank over several independent runs) were estimated to be $0.04 \mu \mathrm{g} / \mathrm{mL}$ ( $\alpha-\mathrm{LA}), 0.05 \mu \mathrm{g} / \mathrm{mL}$ ( $\beta-\mathrm{LG}$ ), $0.03 \mu \mathrm{g} / \mathrm{mL}$ (LF) $(n=6)$. Method precision was estimated from the aggregate of a single-level control $\alpha$-LA $(1 \mu \mathrm{g} / \mathrm{mL}), \beta$-LG $(1 \mu \mathrm{g} / \mathrm{mL})$, LF $(1 \mu \mathrm{g} / \mathrm{mL})$ over multiple independent runs, and the measured RSD were $6.71 \%$, $7.82 \%, 5.13 \%$, respectively $(n=6)$. Between-run precision may be further assessed with RSD 12.31\%, $13.52 \%$, $14.15 \%$, respectively $(n=6)$.

After a simple dilution of commercial milk (200-fold in PBST-EDTA, $\mathrm{pH}$ 7.2), use this calibration curve to calculate the concentration of milks. The recovery study was performed samples of milk purchased from local supermarkets. Free $\alpha$-LA, $\beta$-LG and LF $\left(20 \mu \mathrm{g} \mathrm{L}^{-1}, 100 \mu \mathrm{g}\right.$ $\mathrm{L}^{-1}, 400 \mu \mathrm{g} \mathrm{L}{ }^{-1}$ and $2000 \mu \mathrm{g} \mathrm{L}^{-1}$ ) were spiked in milk solution. The recovery study was performed in three replicates and the results were quite satisfactory as seen in Table 1.

Recovery $=(\mathrm{C} 1-\mathrm{C} 2) / \mathrm{C} 3 \times 100 \%$

C1: Sample concentration after adding standard.

C2: Sample concentration before adding standard.

C3: concentration of adding standard.

\section{Comparison with a reference method-HPLC}

To verify the reliance and accuracy of visualized microarray system, the results of 9 milk samples were compared with an HPLC method. The results obtained by visualized microarray and HPLC are plotted against each other in Fig. 5. The correlation index $\mathrm{r}$ was very good with a linear regression curve of $\mathrm{y}=1.031 \times-9.30$, $r=0.9604$ ( $\alpha$-Lactalbumin); $\mathrm{y}=1.094 \times-35.33, r=0.9872$ ( $\beta$-Lactoglobulin); $\mathrm{y}=1.1096 \times-1.054, r=0.9889$ (Lactoferrin); These results confirm those of the validation experiments. The findings indicate that reliable results can be obtained over the whole concentration range.

\section{Method applications}

The developed procedure was then applied to quantify the concentration of native $\alpha$-LA, $\beta$-LG and LF in three different kinds of milks. The results were shown in Additional file 1, Fig. 6 and Table 2. The precision of the results were well (RSD $<15 \%$ ). As samples, two bovine milks with different processing treatments have been analyzed. Taking into account the calibration curve, it has been determined that raw milk which numbered 1-7 presented highest concentration of $\alpha$ LA, $\beta$-LG and LF,then pasteurized milk $\left(72-85^{\circ} \mathrm{C}\right.$ for $15 \mathrm{~s})$ which numbered $8-11$, UHT milk $\left(135-150{ }^{\circ} \mathrm{C}\right.$ for 4-15 s) including skimmed milk and high calcium milk which numbered $12-18$. As compared to other references that mention the concentration of $\alpha-\mathrm{LA}, \beta$ -

Table 2 Results of a-LA, $\beta-L G$, and LF detected by Visualized Microarray

\begin{tabular}{|c|c|c|c|c|c|c|c|c|c|c|}
\hline \multirow[t]{2}{*}{ Proteins } & \multirow[t]{2}{*}{ number } & \multicolumn{3}{|l|}{ a-Lactalbumin } & \multicolumn{3}{|c|}{$\beta$-Lactoglobulin } & \multicolumn{3}{|l|}{ Lactoferrin } \\
\hline & & Average $(\mu \mathrm{g} / \mathrm{mL})$ & $\mathrm{SD}(\mu \mathrm{g} / \mathrm{mL})$ & $\operatorname{RSD}(n=3)$ & $\begin{array}{l}\text { Average } \\
(\mu \mathrm{g} / \mathrm{mL})\end{array}$ & $\mathrm{SD}(\mu \mathrm{g} / \mathrm{mL})$ & $\operatorname{RSD}(n=3)$ & Average $(\mu \mathrm{g} / \mathrm{mL})$ & $\mathrm{SD}(\mu \mathrm{g} / \mathrm{mL})$ & $\begin{array}{l}\text { RSD } \\
(n=3)\end{array}$ \\
\hline \multirow[t]{7}{*}{ Raw Milk } & 1 & 230.53 & 21.79 & $9.45 \%$ & 490.20 & 60.93 & $12.43 \%$ & 124.2 & 13.23 & $10.65 \%$ \\
\hline & 2 & 80.86 & 8.36 & $10.34 \%$ & 70.70 & 8.29 & $11.73 \%$ & 11.8 & 1.44 & $12.21 \%$ \\
\hline & 3 & 1315.13 & 130.20 & $9.90 \%$ & 983.09 & 104.01 & $10.58 \%$ & 6.1 & 0.69 & $11.23 \%$ \\
\hline & 4 & 653.01 & 79.99 & $12.25 \%$ & 964.84 & 139.42 & $14.45 \%$ & 7.9 & 1.01 & $12.78 \%$ \\
\hline & 5 & 150.21 & 16.88 & $11.24 \%$ & 211.13 & 27.68 & $13.11 \%$ & 28.5 & 3.62 & $12.69 \%$ \\
\hline & 6 & 454.64 & 38.83 & $8.54 \%$ & 440.27 & 41.17 & $9.35 \%$ & 10.3 & 1.12 & $10.88 \%$ \\
\hline & 7 & 811.91 & 107.82 & $13.28 \%$ & 348.66 & 44.84 & $12.86 \%$ & 21.0 & 3.10 & $14.78 \%$ \\
\hline \multirow{4}{*}{$\begin{array}{l}\text { pasteurized } \\
\text { milk }\end{array}$} & 8 & 534.7 & 75.45 & $14.11 \%$ & 499.84 & 67.23 & $13.45 \%$ & 18.7 & 2.58 & $13.80 \%$ \\
\hline & 9 & 199.45 & 19.89 & $9.97 \%$ & 166.57 & 17.79 & $10.68 \%$ & 23.6 & 2.34 & $9.93 \%$ \\
\hline & 10 & 461.9 & 54.23 & $11.74 \%$ & 308.7 & 46.12 & $14.94 \%$ & 15.6 & 2.00 & $12.81 \%$ \\
\hline & 11 & 409.4 & 58.83 & $14.37 \%$ & 243.6 & 32.57 & $13.37 \%$ & 0.0 & - & - \\
\hline \multirow[t]{7}{*}{ UHT Milk } & 12 & 263.6 & 34.00 & $12.90 \%$ & 229.5 & 27.88 & $12.15 \%$ & 0.0 & - & - \\
\hline & 13 & 348.2 & 46.87 & $13.46 \%$ & 205.5 & 29.65 & $14.43 \%$ & 0.0 & - & - \\
\hline & 14 & 264.3 & 33.51 & $12.68 \%$ & 307.6 & 31.87 & $10.36 \%$ & 10.2 & 1.26 & $12.39 \%$ \\
\hline & 15 & 503.0 & 66.30 & $13.18 \%$ & 327.4 & 39.68 & $12.12 \%$ & 6.7 & 0.82 & $12.17 \%$ \\
\hline & 16 & 251.3 & 35.73 & $14.22 \%$ & 169.6 & 23.10 & $13.62 \%$ & 8.1 & 1.01 & $12.51 \%$ \\
\hline & 17 & 579.6 & 60.57 & $10.45 \%$ & 737.0 & 97.21 & $13.19 \%$ & 12.4 & 1.43 & $11.56 \%$ \\
\hline & 18 & 312.8 & 34.10 & $10.90 \%$ & 255.5 & 30.02 & $11.75 \%$ & 0.0 & - & - \\
\hline
\end{tabular}


LG and LF in milk [12, 34, 50]. Now, it is well known that $\alpha$-LA, $\beta$-LG and LF were highly sensitive to temperature.

\section{Conclusions}

In this work, visualized microarray for the high-throughput, specific and sensitive determination of a-LA, $\beta$-LG and LF in milk samples was developed for the first time, without the need for complex or time-consuming pre-treatment steps, following dilution with an appropriate working buffer. The applicability of the visualized microarray asdeveloped was underlined by the implementation and analysis of different milk samples, and the results were validated successfully against a HPLC. The visualized microarray performance is in accordance with such an ELISA kit in terms of rapidity, sensitivity, simplicity and inexpensive, However, ELISA detect $\alpha$-lactoalbumin, $\beta$-lactoglobulin and lactoferrin in milk, it needs at least three times of experiments. Therefore, it has potential as an alternative analytical tool to screen for the presence of a-LA, $\beta$-LG and LF in the dairy industry and pediatric foods. Moreover, the implementation of disposable conjunction with the simplicity, automation and miniaturization of the instrumentation constitute important advantages leading towards the integration of the method in portable (in-field), reliable and userfriendly analytical systems for milk and infant formula quality control.

\section{Additional file}

Additional file 1: Figure S1. The microarray of $a-L A, \beta-L G$, and $L F$ on clear flat-bottom 96-well plate after silver enhancement was imaged with microarray scanner (QARRAY 2000). From top to bottom, left to right was numbered 1 to $18.1-7$ were raw milk, 8-11 were pasteurized milk, 12-18 were UHT milk including skimmed milk and high calcium milk. (JPEG 3520 kb)

\section{Abbreviations \\ AB: Buffer for adjusting $\mathrm{pH}$ of EB; a-LA: a-Lactalbumin; BB: Binding buffer; BSA: Bovine serum albumin; CE: Capillary Electrophoresis; CR: Cross reactivity; EB: Elution buffer; EDTA: Ethylenediaminetetraacetic acid; ELISA: Enzyme-linked immunosorbent assay; FIA: Fluorescent Immunosorbent Assay; HPLC: High performance liquid chromatography; HPLC-MS: High performance liquid chromatography -mass spectra; IAC: Immunoaffinity chromatography; LF: Lactoferrin; PBS: Phosphate buffered saline; RID: Radial Immunodiffusion; RLUs: Relative light units; SDS-PAGE: sodium dodecyl sulfate polyacrylamide gel electrophoresis; SPR: Surface Plasmon Resonance; UHPLC: Ultra high performance liquid chromatography; UHPLC-MS: ultra high performance liquid chromatography - mass spectra; UHT: Ultra-high temperature treated; $\beta$-LG: $\beta$-lactoglobulin}

\section{Acknowledgements}

The authors would like to thank and acknowledge the help of Nanjing Xiangzhong Biotechnology Co. Ltd.

\section{Funding}

We acknowledge financial support of the National Natural Science Foundation of China $(21,405,077,21,227,009,21,475,060)$, Natural Science Foundation of Jiangsu Province (BK20140591). Research Foundation of Jiangsu Province Environmental Monitoring (1116), Special Fund for Agro-scientific research in the Public interest (201403071) and the National Science Fund for Creative Research Groups (21121091).

\section{Availability of data and materials}

The datasets used and analysed during the current study available from the corresponding author on reasonable request.

\section{Authors' contributions}

ZL wrote the manuscript and carried out visualized microarray experiments, including optimization of experimental conditions, determination of cross reaction rate, calculation calibration curves and recovery. FW and NZ performed HPLC measurements, including treatment of milk samples and determination the concentration of $a-L A, \beta-L G, L F$. $Z L$ and JJ performed dairy determination, including evaluation the concentration of $a-L A, \beta-L G, L F$. DX designed the study and assisted in manuscript revision. All authors read and approved the final manuscript.

Ethics approval and consent to participate

Not applicable.

Consent for publication

Not applicable.

\section{Competing interests}

The authors declare that they have no competing interests.

\section{Publisher's Note}

Springer Nature remains neutral with regard to jurisdictional claims in published maps and institutional affiliations.

\section{Author details}

${ }^{1}$ State Key Laboratory of Analytical Chemistry for Life Science, School of Chemistry and Chemical Engineering, Nanjing University, Nanjing 210093, China. ${ }^{2}$ School of Chemistry and Biological Science, Nanjing University Jingling College, Nanjing 210089, China. ${ }^{3}$ Ministry of Agriculture-Key Laboratory of Quality \& Safety Control for Milk and Dairy Products, Institute of Animal Science, Chinese Academy of Agricultural Sciences, Beijing 100193 , People's Republic of China. ${ }^{4}$ Ministry of Agriculture Dairy Quality Supervision and Testing Center, Harbin 150090, China.

Received: 14 May 2017 Accepted: 1 August 2017

Published online: 12 September 2017

\section{References}

1. Chatterton DEW, Smithers G, Roupas P, Brodkorb A. Bioactivity of $\beta$ lactoglobulin and a-lactalbumin-technological implications for processing. Int Dairy J. 2006:16(11):1229-40.

2. Wakabayashi H, Yamauchi K, Takase M. Lactoferrin research, technology and applications. Int Dairy J. 2006:16(11):1241-51.

3. Ferraro V, Madureira AR, Sarmento B, Gomes A, Pintado ME. Study of the interactions between rosmarinic acid and bovine milk whey protein aLactalbumin, $\beta$-Lactoglobulin and Lactoferrin. Food Res Int. 2015;77:450-9.

4. Mayer HK, Raba B, Meier J, Schmid A. RP-HPLC analysis of furosine and acidsoluble $\beta$-lactoglobulin to assess the heat load of extended shelf life milk samples in Austria. Dairy Sci Technol. 2010;90(4):413-28.

5. Anandharamakrishnan C, Rielly CD, Stapley AGF. Loss of solubility of alactalbumin and $\beta$-lactoglobulin during the spray drying of whey proteins. LWT Food Sci Technol. 2008:41(2):270-7.

6. Mudgal P, Daubert CR, Foegeding EA. Kinetic study of $\beta$-lactoglobulin thermal aggregation at low pH. J Food Eng. 2011:106(2):159-65.

7. Yao X, Bunt C, Cornish J, Quek S, Wen J. Improved RP-HPLC method for determination of bovine lactoferrin and its proteolytic degradation in simulated gastrointestinal fluids. Biomed Chromatogr. 2013;27(2):197-202.

8. Sostmann K, Guichard E. Immobilized $\beta$-lactoglobulin on a HPLC-column: a rapid way to determine protein-flavour interactions. Food Chem. 1998;62(4):509-13.

9. Palmano KP, Elgar DF. Detection and quantitation of lactoferrin in bovine whey samples by reversed-phase high-performance liquid chromatography on polystyrene-divinylbenzene. J Chromatogr A. 2002;947(2):307-11.

10. Ding $X$, Yang $Y$, Zhao S, Li Y, Wang Z. Analysis of a-lactalbumin, $\beta$-lactoglobulin $A$ and $B$ in whey protein powder, colostrum, raw milk, and infant formula by CE and LC. Dairy Sci Technol. 2011;91(2):213-25. 
11. Jackson JG, Janszen DB, Lonnerdal B, Lien EL, Pramuk KP, Kuhlman CF. A multinational study of a-lactalbumin concentrations in human milk. J Nutr Biochem. 2004;15(9):517-21.

12. Boitz LI, Fiechter G, Seifried RK, Mayer HK. A novel ultra-high performance liquid chromatography method for the rapid determination of $\beta$-lactoglobulin as heat load indicator in commercial milk samples. J Chromatogr A. 2015;1386:98-102.

13. Muhammad G, Saïd B, Thomas C. Structural consequences of dry heating on Beta-Lactoglobulin under controlled pH. Procedia Food Sci. 2011;1:391-8.

14. Gulzar M, Bouhallab S, Jardin J, Briard-Bion V, Croguennec T. Structural consequences of dry heating on alpha-lactalbumin and beta-lactoglobulin at pH 6.5. Food Res Int. 2013;51(2):899-906.

15. Corzo-Martínez M, Moreno FJ, Olano A, Villamiel M. Structural characterization of bovine $\beta$-Lactoglobulin-Galactose/Tagatose Maillard complexes by Electrophoretic, chromatographic, and spectroscopic methods. J Agric Food Chem. 2008;56(11):4244-52.

16. Yan R, Qu L, Luo N, Liu Y, Liu Y, Li L, Chen L. Quantitation ofa -Lactalbumin by liquid chromatography tandem mass spectrometry in medicinal adjuvant lactose. Int J Anal Chem. 2014;2014:1-4.

17. Stojadinovic M, Burazer L, Ercili-Cura D, Sancho A, Buchert J, Velickovic TC, Stanic-Vucinic D. One-step method for isolation and purification of native B-lactoglobulin from bovine whey. J Sci Food Agr. 2012;92(7):1432-40.

18. Silveira ST, Martínez-Maqueda D, Recio I, Hernández-Ledesma B. Dipeptidyl peptidase-IV inhibitory peptides generated by tryptic hydrolysis of a whey protein concentrate rich in $\beta$-lactoglobulin. Food Chem. 2013;141(2):1072-7.

19. Yang $W$, Liqing $W$, Fei $D$, Bin $Y$, Yi $Y$, Jing $W$. Development of an Sl-traceable HPLC-isotope dilution mass spectrometry method to quantify $\beta$ Lactoglobulin in milk powders. J Agric Food Chem. 2014;62(14):3073-80

20. Cunsolo V, Costa A, Saletti R, Muccilli V, Foti S. Detection and sequence determination of a new variant $\beta$-lactoglobulin II from donkey. Rapid Commun Mass Sp. 2007;21(8):1438-46.

21. Czerwenka C, Maier I, Potocnik N, Pittner F, Lindner W. Absolute Quantitation of $\beta$-Lactoglobulin by protein liquid chromatography-mass spectrometry and its application to different milk products. Anal Chem. 2007;79(14):5165-72.

22. Chen Q, Zhang J, Ke X, Lai S, Li D, Yang J, Mo W, Ren Y. Simultaneous quantification of $a$-lactalbumin and $\beta$-casein in human milk using ultraperformance liquid chromatography with tandem mass spectrometry based on their signature peptides and winged isotope internal standards. Biochim Biophys Acta. 2016;1864(9):1122-7.

23. Xing K, Chen Q, Pan X. Quantification of lactoferrin in breast milk by ultrahigh performance liquid chromatography-tandem mass spectrometry with isotopic dilution. RSC Adv. 2016;6(15):12280-5.

24. Ren Y, Han Z, Chu X, Zhang J, Cai Z, Wu Y. Simultaneous determination of bovine a-lactalbumin and $\beta$-lactoglobulin in infant formulae by ultra-highperformance liquid chromatography-mass spectrometry. Anal Chim Acta. 2010;667(1-2):96-102.

25. Zhang J, Lai S, Cai Z, Chen Q, Huang B, Ren Y. Determination of bovine lactoferrin in dairy products by ultra-high performance liquid chromatographytandem mass spectrometry based on tryptic signature peptides employing an isotope-labeled winged peptide as internal standard. Anal Chim Acta. 2014;829:33-9.

26. Puerta A, Diez-Masa JC, de Frutos M. Immunochromatographic determination of $\beta$-lactoglobulin and its antigenic peptides in hypoallergenic formulas. Int Dairy J. 2006;16(5):406-14.

27. Puerta A, Diez-Masa JC, de Frutos M. Development of an immunochromatographic method to determine $\beta$-lactoglobulin at trace levels. Anal Chim Acta. 2005;537(1-2):69-80

28. Mazri C, Sánchez L, Ramos SJ, Calvo M, Pérez MD. Effect of high-pressure treatment on denaturation of bovine $\beta$-lactoglobulin and a-lactalbumin. Eur Food Res Technol. 2012;234(5):813-9.

29. Alomirah HF, Alli I. Separation and characterization of $\beta$-lactoglobulin and a-lactalbumin from whey and whey protein preparations. Int Dairy J. 2004;14(5):411-9.

30. Giacinti G, Basiricò L, Ronchi B, Bernabucci U. Lactoferrin concentration in buffalo milk. Ital J Anim Sci. 2013;12(1):e23.

31. Cheang B, Zydney AL. Separation of -Lactalbumin and -Lactoglobulin using membrane Ultrafiltration. Biotechnol Bioeng. 2003:83(2):201-9.

32. Li J, Ding X, Chen Y, Song B, Zhao S, Wang Z. Determination of bovine lactoferrin in infant formula by capillary electrophoresis with ultraviolet detection. J Chromatogr A. 2012;1244:178-83.
33. Gutierrez JEN, Jakobovits L. Capillary electrophoresis of a-Lactalbumin in milk powders. J Agric Food Chem. 2003:51(11):3280-6.

34. Chen H, Busnel J, Gassner A, Peltre G, Zhang X, Girault HH. Capillary electrophoresis immunoassay using magnetic beads. Electrophoresis. 2008;29(16):3414-21.

35. Liu L, Kong D, Xing C, Zhang X, Kuang H, Xu C. Sandwich immunoassay for lactoferrin detection in milk powder. Anal Methods UK. 2014;6(13):4742.

36. Wroblewska B, Karamac M, Amarowicz R, Szymkiewicz A, Troszynska A, Kubicka E. Immunoreactive properties of peptide fractions of cow whey milk proteins after enzymatic hydrolysis. Int J Food Sci Technol. 2004;39(8):839-50.

37. de Luis R, Lavilla M, Sánchez L, Calvo M, Pérez MD. Development and evaluation of two ELISA formats for the detection of $\beta$-lactoglobulin in model processed and commercial foods. Food Control. 2009;20(7):643-7.

38. Huang YQ, Morimoto K, Hosoda K, Yoshimura Y, Isobe N. Differential immunolocalization between lingual antimicrobial peptide and lactoferrin in mammary gland of dairy cows. Vet Immunol Immunopathol. 2012;145(1-2):499-504.

39. Pelaez-Lorenzo C, Diez-Masa JC, Vasallo I, de Frutos M. Development of an optimized ELISA and a sample preparation method for the detection of $\beta$ Lactoglobulin traces in baby foods. J Agric Food Chem. 2010;58(3):1664-71.

40. Manzo C, Pizzano R, Addeo F. Detection of pH 4.6 insoluble $\beta$-Lactoglobulin in heat-treated milk and mozzarella cheese. J Agric Food Chem. 2008;56(17):7929-33.

41. Mehta R, Petrova A. Biologically active breast milk proteins in association with very preterm delivery and stage of lactation. J Perinatol. 2011;31(1):58-62.

42. Kleber N, Maier S, Hinrichs J. Antigenic response of bovine $\beta$-lactoglobulin influenced by ultra-high pressure treatment and temperature. Innov Food Sci Emerg. 2007:8(1):39-45.

43. Finetti C, Plavisch L, Chiari M. Use of quantum dots as mass and fluorescence labels in microarray biosensing. Talanta. 2016;147:397-401.

44. Yang A, Zheng Y, Long C, Chen H, Liu B, Li X, Yuan J, Cheng F. Fluorescent immunosorbent assay for the detection of alpha lactalbumin in dairy products with monoclonal antibody bioconjugated with CdSe/ZnS quantum dots. Food Chem. 2014;150:73-9.

45. Billakanti JM, Fee CJ, Lane FR, Kash AS, Fredericks R. Simultaneous, quantitative detection of five whey proteins in multiple samples by surface plasmon resonance. Int Dairy J. 2010;20(2):96-105.

46. Tomassetti M, Martini E, Campanella L, Favero G, Sanzò G, Mazzei F. Lactoferrin determination using flow or batch immunosensor surface plasmon resonance: comparison with amperometric and screen-printed immunosensor methods. Sensors Actuators B Chem. 2013;179:215-25.

47. Indyk HE, McGrail IJ, Watene GA, Filonzi EL. Optical biosensor analysis of the heat denaturation of bovine lactoferrin. Food Chem. 2007;101(2):838-44.

48. Indyk HE. Development and application of an optical biosensor immunoassay for a-lactalbumin in bovine milk. Int Dairy J. 2009;19(1):36-42.

49. Indyk HE, Filonzi EL. Determination of lactoferrin in bovine milk, colostrum and infant formulas by optical biosensor analysis. Int Dairy J. 2005;15(5):429-38.

50. Ruiz-Valdepeñas Montiel V, Campuzano S, Torrente-Rodríguez RM, Reviejo AJ, Pingarrón JM. Electrochemical magnetic beads-based immunosensing platform for the determination of a-lactalbumin in milk. Food Chem. 2016;213:595-601

51. Eissa S, Tlili C, L'Hocine L, Zourob M. Electrochemical immunosensor for the milk allergen $\beta$-lactoglobulin based on electrografting of organic film on graphene modified screen-printed carbon electrodes. Biosens Bioelectron. 2012;38(1):308-13

52. Hohensinner $V$, Maier I, Pittner F. A 'gold cluster-linked immunosorbent assay': optical near-field biosensor chip for the detection of allergenic $\beta$ lactoglobulin in processed milk matrices. J Biotechnol. 2007;130(4):385-8.

53. Li Z, Li Z, Zhao D. Smartphone-based visualized microarray detection for multiplexed harmful substances in milk. Biosens Bioelectron. 2017:87:874-80.

54. Li Z, Li Z, Niu Q. Visual microarray detection for human lgE based on silvernanoparticles. Sensors Actuators B Chem. 2017;239:45-51.

55. Li Z, Li Z, Jiang J. Simultaneous detection of various contaminants in milk based on visualized microarray. Food Control. 2017;73:994-1001.

56. Li Z, Li Z, Xu D. Simultaneous detection of four nitrofuran metabolites in honey simultaneous detection of four nitrofuran metabolites in honey by using a visualized microarray screen assay. Food Chem. 2017;221:1813-21. 